\title{
A IMPORTÂNCIA DA IDENTIDADE VISUAL: caso dos bordadeiros de filé do Pontal da Barra, Maceió - Alagoas
}

Layane Nascimento de Araúio

Juliana Donato de Almeida Cantalice

\begin{abstract}
Resumo: Têm-se que uma Identidade Visual bem estruturada oferece muitas vantagens competitivas à uma empresa, seja ela de grande ou pequeno porte. Dessa forma, o objetivo deste artigo é investigar de que maneira uma Identidade Visual estruturada e planejada dentro dos princípios do design traz benefícios e vantagens para autônomos e pequenas empresas no ramo artesanal. A pesquisa se configura em um Estudo de Caso situado no Bairro do Pontal da Barra, em Maceió, Alagoas, com os bordadeiros de filé da região, tentando compreender quais são as expectativas e realidades dos artesãos e suas percepções em relação a valorização e a venda do filé através de um comparativo entre os que possuem marca e os que não possuem.
\end{abstract}

Palavras-chave: Design, Identidade Visual, Comunicação, Artesanato, Filé

\section{INTRODUC̣ÃO}

Após o período da globalização, o comércio mundial se tornou mais acirrado e competitivo em virtude do avanço tecnológico. Com isso, novas ferramentas e métodos foram desenvolvidos e implementados às empresas, com o objetivo de potencializar estratégias de divulgação e vendas dos produtos. E assim, o design foi se aprimorando através de novas pesquisas e técnicas com o objetivo de valorizar e destacar empreendimentos frente ao mercado, para tanto a construção da marca de uma empresa se mostrou fator de necessidade e originalidade para que a mesma destaque a si e a seus produtos dos demais.

Desse modo, Wheeler (2006) afirma que a marca é uma ideia, expectativa e promessa que reside na mente do consumidor à respeito do produto ou serviço oferecido, com isso as pessoas se encantam, confiam na marca e em tudo que ela representa. Assim, corroborando com a afirmação de Wheeler, Uchiyama (2013) coloca que a construção de uma marca forte pede uma identidade visual coerente com o posicionamento da empresa. Logo o consumidor, por meio da identidade visual, tem uma percepção sobre a empresa, seus produtos e sua entrega de serviços. Ou seja, os mesmos julgam através destas associações se a empresa será capaz de satisfazer ou não seus anseios e desejos. Portanto, investir e elaborar uma marca forte com uma identidade visual estruturada e planejada dentro dos princípios do design pode significar uma maior possibilidade de se sobressair e ter maior visibilidade no ambiente mercadológico, chegando mais próximo ao consumidor.

Esta pesquisa, então, se configura em um estudo de caso a partir de dados 
coletados no bairro do Pontal da Barra em Maceió, Alagoas, com os bordadeiros de filé da região, uma tipologia artesanal reconhecida como patrimônio imaterial cultural do estado pelo IPHAN (Instituto Patrimônio Histórico e Artístico Nacional). A mesma tem por objetivo analisar as diferenças entre os bordadeiros locais que possuem marca e identidade visual e os que não possuem, observando como esta distinção afeta as questões relacionadas ao comércio da mercadoria e a valorização do filé. Para tanto, foram utilizados métodos interacionais (ação conversacional, verbalizações espontâneas, provocadas e escuta ampliada) e métodos observacionais (observação da atividade, fotografias e filmagens), para coleta e análise de dados dos bordadeiros a respeito dos parâmetros projetuais, que se configuram no processo de produção do ofício e sua comercialização. Ao final desta análise preliminar, foi confirmada a hipótese inicial levantada a respeito da influência da identidade visual em comunidades produtoras de artesanato, nota-se que os bordadeiros que possuem marca e identidade visual apresentam melhor destaque de seus produtos frente aos consumidores e a concorrência local.

\section{MARCA, IDENTIDADE VISUAL, COMUNICAÇÃO E O BORDADO FILÉ}

O artesanato brasileiro tem mais de cinco séculos de história e tradição, sendo a forma de expressão mais usual de uma população que lida diariamente com matériasprimas simples que, com mãos habilidosas, as transformam em arte. Desse modo, o conhecimento, que é transmitido entre os indivíduos de geração em geração se dá baseado na experiência e é o responsável, em maior escala, pela realização da atividade.

Caracterizado pela técnica e arte realizada manualmente, o artesanato compreende tanto valores simbólicos, culturais, quanto sociais, uma vez que em sua prática, empregam-se materiais e recursos do próprio ambiente com características locais e regionais, cuja passagem de conhecimentos ocorre tacitamente.

Neste âmbito, em Maceió - AL, um grupo de artesãos trabalham produzindo o bordado filé no bairro do Pontal da Barra, localizado às margens da Lagoa Mundaú, como pode ser visto na Figura 1. Segundo a Secretaria de Estado do Planejamento e do Desenvolvimento Econômico - Seplande, através do Programa de Artesanato Brasileiro - PAB, em abril de 2014, somente para essa tipologia de bordado foram emitidas em Alagoas, 860 carteiras de artesãos em Maceió, 626 em Marechal Deodoro e 21 em Coqueiro Seco, totalizando 1.507 emissões de carteiras de artesãos com domicílio na área das lagoas Mundaú e Manguaba na modalidade de filé. 
Figura 1 - Localização da produção de Filé em Alagoas. Fonte: autores, 2017.

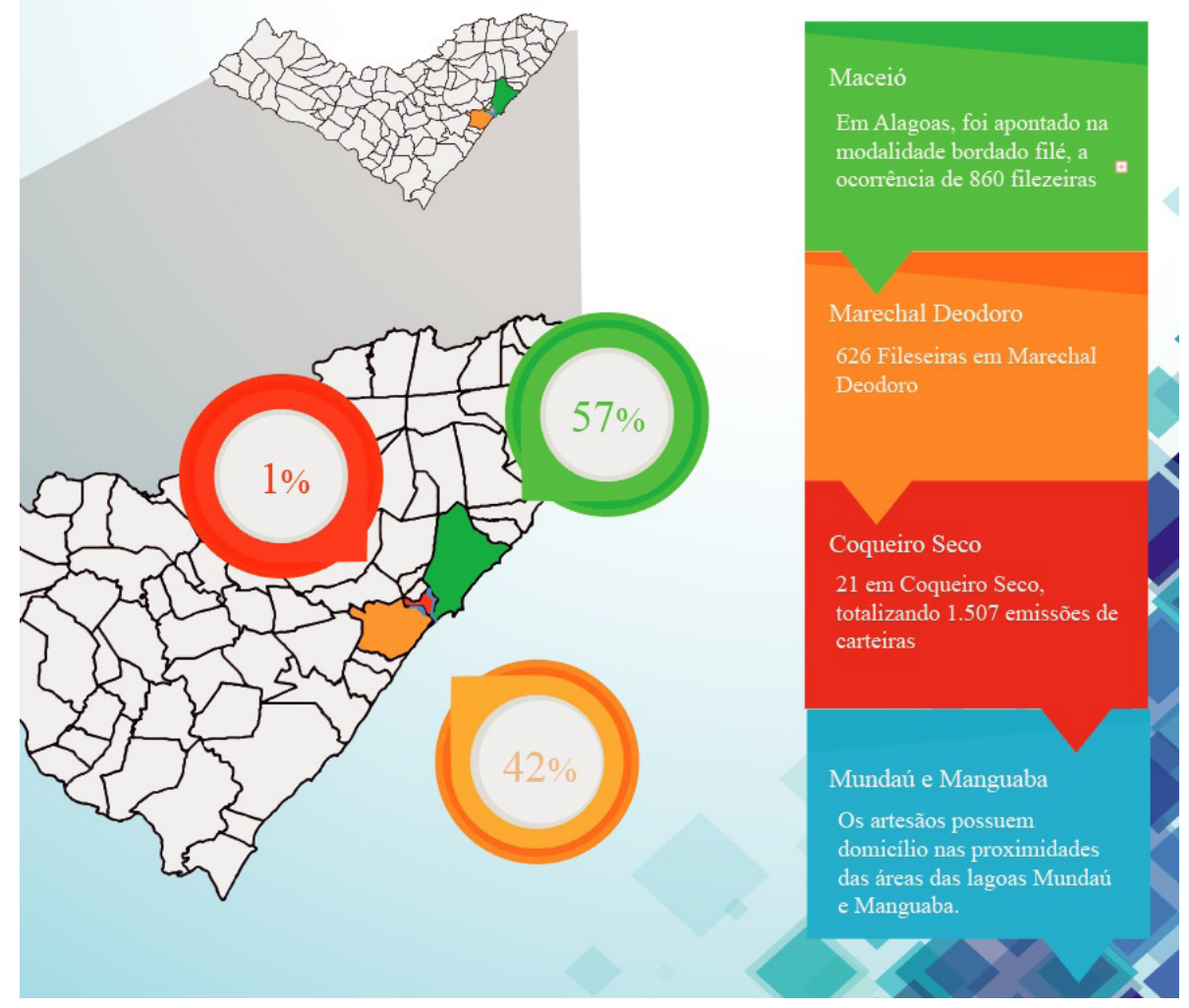

Barros (2008), descreve o filé como uma tipologia do artesanato que consiste em um bordado sobre uma rede semelhante às usadas pelos pescadores da localidade, sua suposta origem é derivada do fato de que as mulheres dos pescadores da região ao fazerem e consertarem as redes de seus esposos, descobriram que era possível executar trabalhos artesanais utilizando-se do mesmo procedimento. Como pode observado na Figura 2 abaixo.

Figura 2 - Filé preso na rede em um tear de madeira. Fonte: autores, 2017.

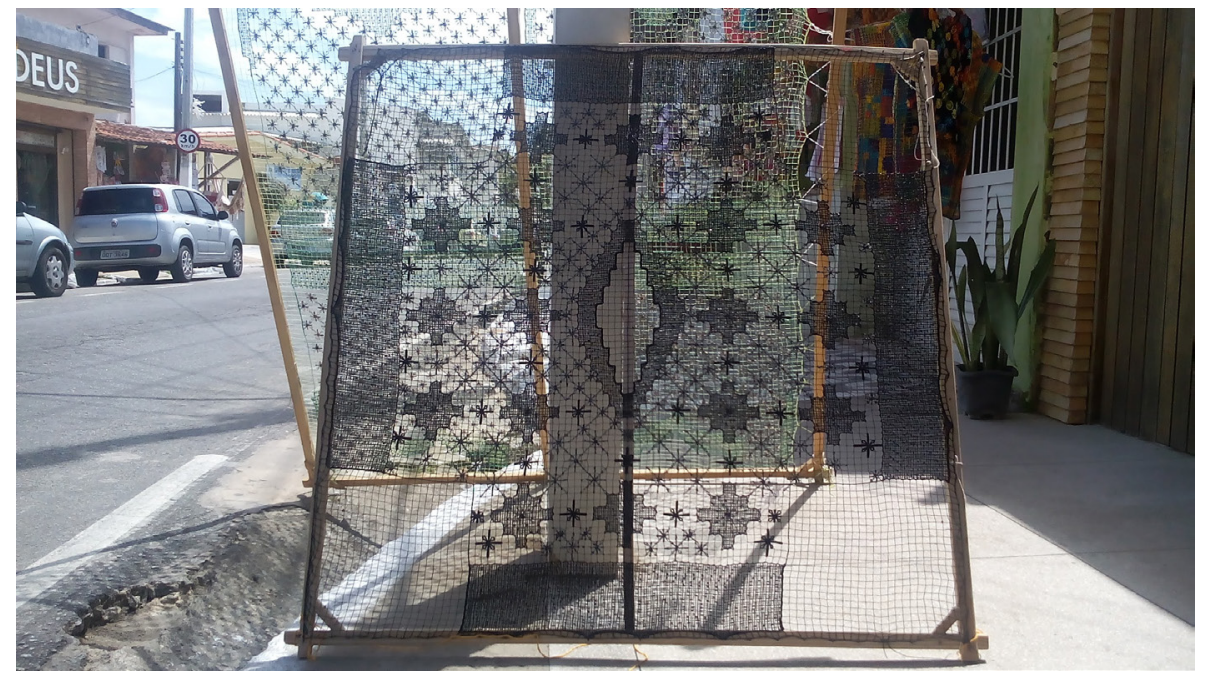

Foi realizada uma pesquisa preliminar no bairro Pontal da Barra em Maceió-AL, com 45 bordadeiros que trabalham num local conhecido como "rua das rendeiras", como mostra a Figura 3, localizado às margens da Lagoa Mundaú. Foram levantados dados à respeito do ofício e da comercialização do filé, referentes à existência ou não da identidade visual nas unidades autônomas e associações analisadas, se a mesma é percebida como parte importante do negócio e sua influência na comercialização. 
Figura 3 - Rua das rendeiras, bairro do Pontal da Barra, Maceió - AL. Fonte: Autores, 2017.

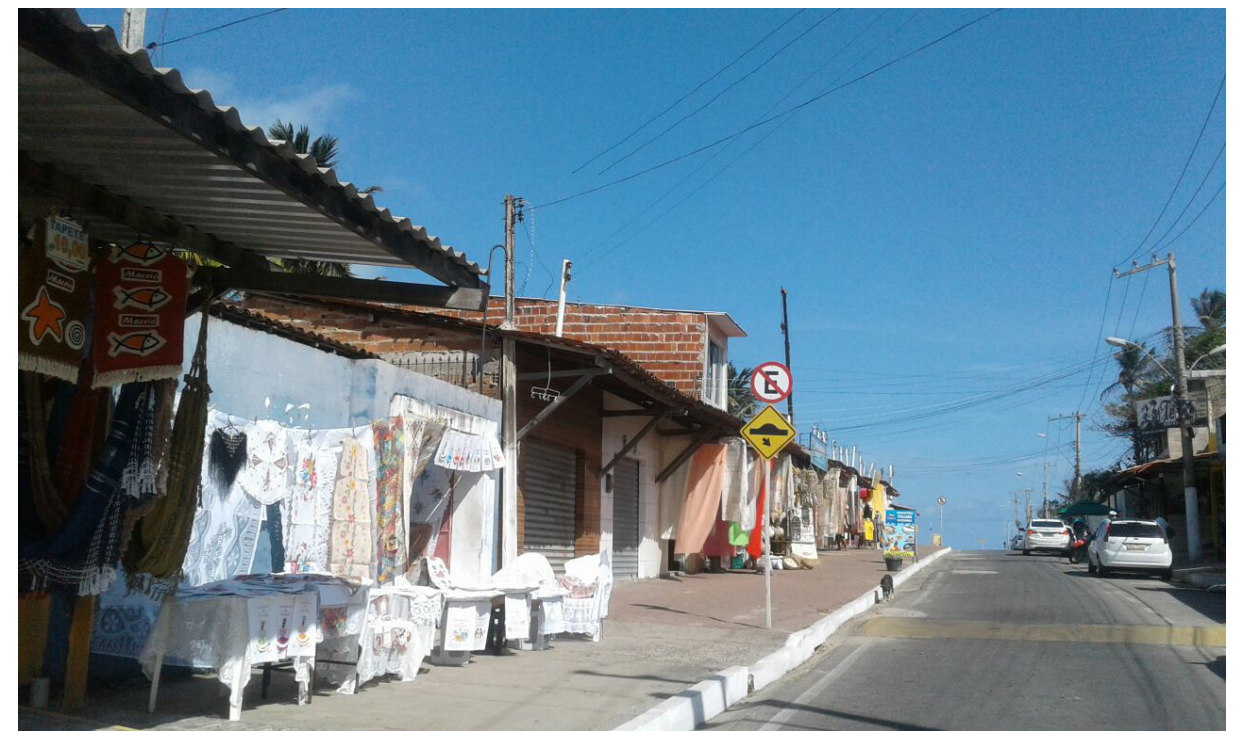

Constatou-se que os artesãos da região não possuem um Estatuto local para identificação e padronização do trabalho dos mesmos, embora exista uma Associação Geral dos Bordadeiros de Filé do Bairro do Pontal da Barra, essa não possui uma sede fixa para reunião dos bordadeiros locais sendo suas reuniões realizadas nas casas dos próprios artesãos participantes uma vez ao mês. Nessas ocasiões, são decididos fatores como o revezamento entre os bordadeiros para que os mesmos possam levar os produtos de filé da comunidade para os hotéis da cidade, localizados em bairros mais distantes e turísticos, como o bairro de Ponta Verde e Pajuçara, com o intuito de comercialização dos produtos e divulgação dos mesmos e do bairro do Pontal da Barra. Tal propagação faz-se necessária em virtude da falta de uma maior disseminação local, a promoção individual das peças de filé auxiliam na divulgação do artesanato assim os turistas tomam conhecimento do produto e do bairro e se interessam por fim, visitá-lo.

A associação possui em média 600 bordadeiros associados dos quais 42 que participam regularmente das reuniões e pagam sua taxa mensal de 20 reais. Cada bordadeiro é responsável pelo seu próprio negócio, seja sua loja ou fazer o filé sob encomendas. As bordadeiras, embora aliadas a um grupo maior, como a associação, geralmente trabalham de maneira individual, com suas próprias metas e encomendas.

Além da Associação geral, encontra-se no bairro um grupo de "filezeiras" locais que reuniram-se e fundaram o INBORDAL, Instituto do Bordado Filé de Alagoas, com o objetivo de "Proteger a tradição do Bordado Filé da Região das Lagoas Mundaú e Manguaba, garantindo produtos de qualidade, fortalecendo e promovendo esse ofício tradicional que foi registrado como Patrimônio Cultural Imaterial de Alagoas" (INBORDAL, 2016).

Esses fatores levaram os mesmos a concorrência local, uma vez que cada produto é de cunho manual e apresenta exclusividade pelas mãos do artesão que o desenvolveu, não obstante, acabam perdendo no quesito identificação e originalidade, uma vez que ao sair do local, as peças produzidas individualmente, sem vínculo a algumas lojas locais ou ao Instituto INBORDAL que possuem identificação visual e marcas estabelecidas, passam apenas a serem conhecidas como de origem Alagoana, sem valorizar individualmente o responsável pelo trabalho.

O artesão, seja ele pequeno ou micro-empreendedor, pode fazer uso dos critérios do design gráfico como fator de destaque no mercado. O design, quando aplicado de modo sagaz em uma empresa, na elaboração de sua marca e de sua identidade visual, pode trazer benefícios e um diferencial que chama a atenção do consumidor, valorizando-a 
frente ao seu concorrente, uma vez que, as peças artesanais são bastante personalizadas e suas produções geralmente ocorrem em pequenos locais ocasionando uma baixa produtividade.

Desse modo, a marca é responsável pela identificação da empresa e/ou do produto oferecido. É através da marca que uma empresa e/ou produto garante sua consolidação no mercado, uma vez que ela se trata de um atributo visual e comunicativo, seja um signo, símbolo ou mesmo uma palavra, que permite identificar e diferenciar os mesmos de seus similares. De acordo com Wheeler (2006), a marca é sinônimo do nome da empresa e sua reputação, possuindo força como símbolo cultural. Dessa maneira, ao analisar uma marca, analisa-se concomitantemente sua capacidade de representação do que está sendo proposto. Assim, Kapferer (1998, apud Vásquez 2007), afirma que:

uma marca é ao mesmo tempo, signo, palavra, objeto, conceito. Signo, pois a marca é multiforme: ela integra os signos figurativos, como o logotipo, o emblema, as cores, as formas, as embalagens e o design. Palavra, no caso o nome da marca, que é o suporte de informação oral e escrita sobre o produto. Objeto, pois a marca distingue um ou vários produtos de outros produtos ou serviços. Conceito, enfim, pois a marca, como todo signo, tem um significado, ou seja, um sentido (KAPFERER, 1998, p.190).

Segundo Vásquez (2007), a marca permite ao consumidor identificar, distinguir, comparar e criar preferências com relação ao mercado. No cenário dos bordadeiros de filé, seria então estabelecida uma ponte entre consumidor-produto, por meio de um vínculo emocional e social. Tais princípios são reforçados também por Péon, que enfatiza o posicionamento da instituição diante dos concorrentes de mercado, com clara diferenciação visual e facilidade de identificação. Ele enfatiza ainda, a necessidade de noções de solidez, segurança, organização, planificação e univocidade na marca, a fim de consolidar sua individualidade e não passar a ideia de ser passageira.

A seguir será apresentada uma análise comparativa mercadológica do filé dos bordadeiros do bairro do Pontal da Barra e em como a identidade visual pode ser utilizada como estratégia de destaque nos negócios.

\section{ANÁLISE COMPARATIVA MERCADOLÓGICA DO FILÉ: A IMPORTÂNCIA DA IDENTIDADE VI- SUAL PARA COMUNIDADES PRODUTORAS DE ARTESANATO}

Apesar dessa tipologia de bordado ser uma das principais fontes de renda da população das Lagoas Mundaú, de acordo com o levantamento de dados, não há muita valorização das peças, seja por falta de reconhecimento pelos consumidores que não conhecem os processos envolvidos, ou falta de visão empreendedora por parte dos produtores, assim as peças acabam sendo vendidas a preços abaixo do mercado. Uma peça pequena, como um Sousplat - suplá para pratos, como mostra a Figura 4, vendido em torno de 25,00 reais, geralmente despende no mínimo de uma jornada de trabalho de 8 à 10 horas para ser confeccionada, além dos materiais utilizados para a confecção da mesma, que são um tear de madeira, uma rede, agulha e linhas. Logo, como a produção ocorre de forma lenta, considerando-se as horas empenhadas no trabalho e a mão de obra aplicada é possível compreender que a rentabilidade não compensa.

A produção e a comercialização acontece no próprio local, na maioria das vezes em frente às casas e lojas locais pertencentes aos bordadeiros como pode ser observado na Figura 3. Mensalmente são vendidas aproximadamente 15 peças, sendo as menores e mais baratas como sousplats, apoiador de copos, acessórios e camisetas, mais facilmente vendidas, assim o nicho de mercado local é composto basicamente de turistas ou encomendas da região. A média de lucro das lojas dos artesãos do bordado é geralmente inferior a mil reais mensais. No entanto, os bordadeiros que trabalham por conta própria, não vinculadas às lojas, obtém geralmente um salário bem inferior ao 
mínimo, que equivale a novecentos e trinta e sete reais (até o momento do levantamento de dados para a elaboração deste trabalho). Contudo, esses dados são referentes à alta temporada, período que coincide com as estações de primavera e verão do hemisfério sul. Logo, na baixa temporada o lucro mensal é consequentemente inferior aos valores apresentados.

Figura 4 - Sousplat - suplá para pratos de filé. Fonte: autores, 2017.

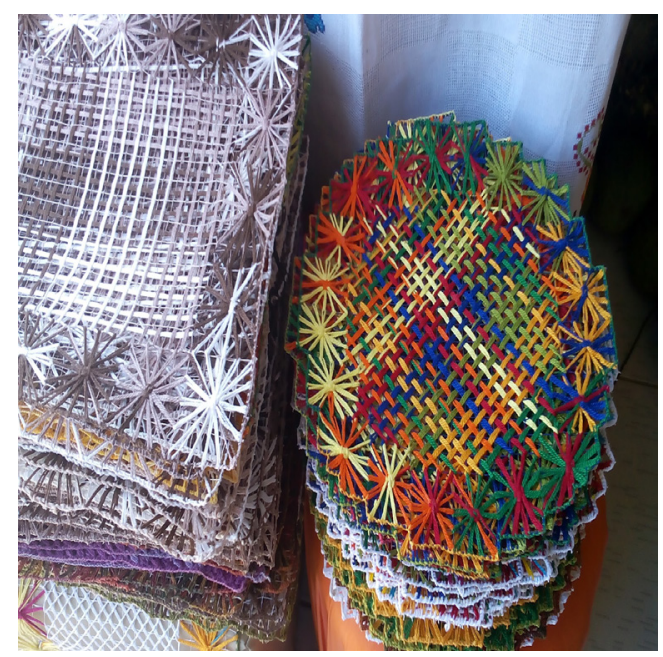

Um pequeno número de lojas locais, já buscam desenvolver suas marcas próprias, como pode ser visto na Figura 5 abaixo, o que pode proporcionar maior comunicação da empresa com seus consumidores. Tal comunicação, no entanto, se dá através da identidade da marca e da imagem construída e transmitida pela mesma. O processo comunicativo acontece pela relação entre um emissor e um receptor. Nesse caso a informação é transmitida do emissor - artesãos - para seu receptor - consumidores em questão, através do sistema de Identidade Visual dos mesmos. Tal relação acaba por garantir maior exclusividade, identificação e valorização das peças produzidas.

Figura 5 - Algumas das marcas das lojas de filé encontradas na "rua das rendeiras". Fonte: autores, 2017.

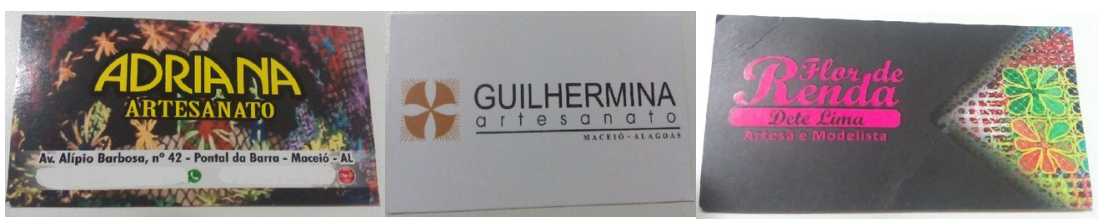

Sendo assim, o Instituto INBORDAL, criado em 2014 pelo SEBRAE (Serviço Brasileiro de Apoio às Micro e Pequenas Empresas) do estado de Alagoas, possui em torno de 30 bordadeiros locais associadas ao mesmo e apresenta maior visibilidade à respeito do trabalho artesanal executado pelas bordadeiros que fazem parte dele, já que a marca do Instituto já alcançou âmbito internacional através do site do mesmo - www.inbordal. org.br, exposições em hotéis, eventos, revistas e está diretamente ligada a tipologia filé quando pesquisado através da web.

As encomendas e produções que são direcionadas ao Instituto, geralmente encomendas de médio e grande porte para empresas, exposições, feiras, desfiles, entre outras, são recebidas pelo mesmo e distribuídas entre suas associadas. As mesmas pagam uma porcentagem do lucro final ao Instituto para manutenção do mesmo, mas através de coleta de dados, têm-se que as mesmas recebem em torno de um salário mínimo mensal, apenas com sua associação ao Instituto, não levando em consideração serviços externos.

A marca do Instituto foi criada em 2016, bem como seu Sistema de Identidade Visual, 
através de um projeto do SEBRAE - AL de valorização da produção artesanal local, nesse caso do filé. A mesma é formada por um sistema de identidade visual composta por símbolo e um nome como mostra a Figura 6. Essa configuração integrada de imagem e texto é denominada Isologo e como principal característica temos esta integração entre os elementos, que não podem de forma alguma serem utilizados separadamente, a fim de manter a integridade visual e não descaracterizar a mesma.

Figura 6 - Marca do Instituto INBORDAL. Fonte: INBORDAL, 2017.

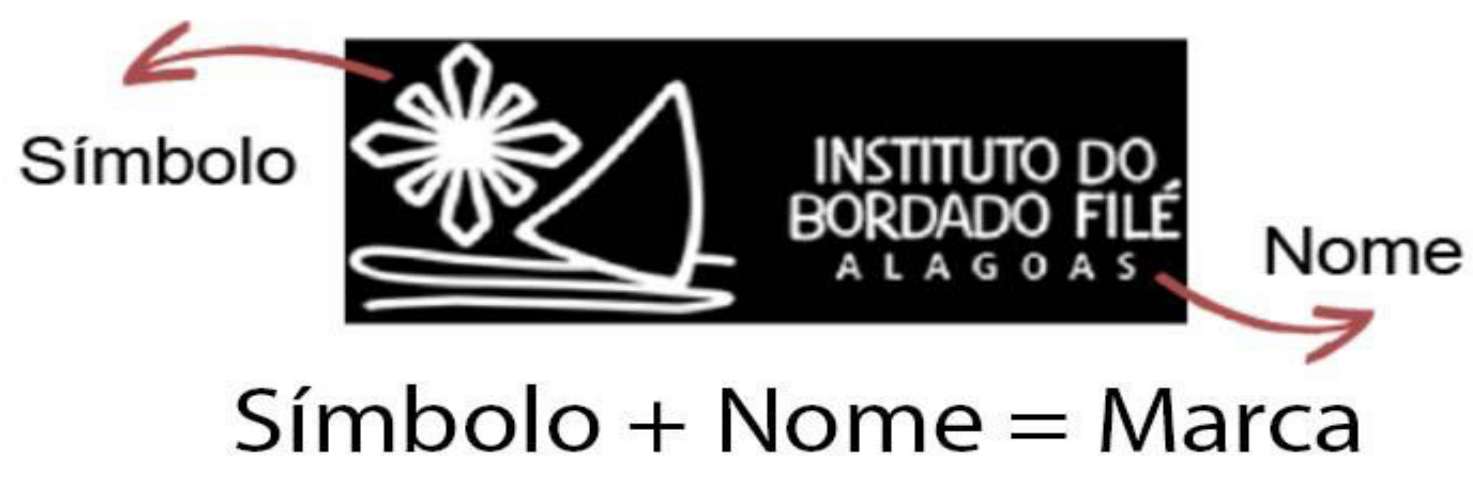

\section{* não podem ser usados separadamente}

A seguir, será apresentada um quadro com o intuito de mostrar as demandas identificadas com base na análise preliminar dos bordadeiros de filé com Identidade Visual e sem Identidade Visual, sendo os que possuem identidade divididos em dois grupos, os das filezeiras do INBORDAL e os lojistas, além de fazer um comparativo entre os mesmos à respeito da comercialização de seus produtos.

Quadro 1 - Análise mercadológica preliminar dos bordadeiros de filé do Pontal da Barra, Maceió - AL.

\begin{tabular}{l|l|l|l}
$\begin{array}{l}\text { A N Á L I S E } \\
\text { MERCADOLÓ- } \\
\text { GlCA }\end{array}$ & $\begin{array}{l}\text { Bordadeiras autônomas } \\
\text { (sem Identidade Visual) }\end{array}$ & $\begin{array}{l}\text { Bordadeiras Lojistas } \\
\text { (com Identidade Visual) }\end{array}$ & $\begin{array}{l}\text { Bordadeiras associadas } \\
\text { ao INBORDAL }\end{array}$ \\
\hline $\begin{array}{l}\text { Nicho de mer- } \\
\text { cado }\end{array}$ & $\begin{array}{l}\text { Turistas que visitam o lo- } \\
\text { cal, consumidores locais } \\
\text { e pequenas encomen- } \\
\text { das. }\end{array}$ & $\begin{array}{l}\text { Turistas que visitam o lo- } \\
\text { cal, consumidores locais } \\
\text { e pequenas encomendas. }\end{array}$ & $\begin{array}{l}\text { Turistas que visitam o } \\
\text { local, consumidores na- } \\
\text { cionais e internacionais, } \\
\text { grandes encomendas e } \\
\text { exposições. }\end{array}$ \\
\hline $\begin{array}{l}\text { Média de ren- } \\
\text { da mensal }\end{array}$ & $\begin{array}{l}\text { Abaixo de um salário mí- } \\
\text { nimo (R\$ 937,00.) }\end{array}$ & $\begin{array}{l}\text { Aproximadamente } \\
\text { RS 1000,00, dependen- } \\
\text { do do movimento turísti- } \\
\text { co do local. }\end{array}$ & $\begin{array}{l}\text { Somente com o grupo do } \\
\text { INBORDAL as bordadeiras } \\
\text { arrecadam em torno de } \\
\text { um salário mínimo, sem } \\
\text { levar em consideração } \\
\text { suas lojas e peças autô- } \\
\text { nomas. }\end{array}$ \\
\hline $\begin{array}{l}\text { Média de pe- } \\
\text { ças vendidas } \\
\text { mensalmente }\end{array}$ & $\begin{array}{l}\text { Abaixo de 10 peças, ge- } \\
\text { ralmente vendidas sob } \\
\text { encomenda para as lojis- } \\
\text { tas locais. }\end{array}$ & $\begin{array}{l}\text { Aproximadamente } \\
\text { 15 peças. }\end{array}$ & $\begin{array}{l}\text { orupo recebe muitas } \\
\text { encomendas externas, } \\
\text { além dos trabalhos indivi- } \\
\text { duais de cada artesão as- } \\
\text { sociado, logo individual- } \\
\text { mente pode-se estimar } \\
\text { um valor de aproximada- } \\
\text { mente 20 peças produzi- } \\
\text { das. }\end{array}$ \\
\hline
\end{tabular}




\begin{tabular}{|c|c|c|c|}
\hline $\begin{array}{l}\text { Principais pe- } \\
\text { ças vendidas }\end{array}$ & $\begin{array}{l}\text { Geralmente menores } \\
\text { e de baixo custo, como } \\
\text { panos de pratos, sous- } \\
\text { plats; E algumas peças } \\
\text { maiores geralmente sob } \\
\text { encomenda para as lojis- } \\
\text { tas locais, como camise- } \\
\text { tas femininas, caminhos } \\
\text { de mesa, entre outras. }\end{array}$ & $\begin{array}{l}\text { Peças menores e de bai- } \\
\text { xo custo em sua maioria, } \\
\text { como panos de pratos, } \\
\text { tiaras, colares, chapéus } \\
\text { e peças maiores como } \\
\text { camisas, caminhos de } \\
\text { mesa, vestidos e saídas } \\
\text { de praia. }\end{array}$ & $\begin{array}{l}\text { Todos os tipos de peças, } \\
\text { inclusive peças fashio- } \\
\text { nistas para exposições } \\
\text { e desfiles, como aces- } \\
\text { sórios e aplicações em } \\
\text { peças mais sofisticadas } \\
\text { como vestidos. }\end{array}$ \\
\hline Visibilid & Local & Nacional & Internacional \\
\hline
\end{tabular}

Assim, os bordadeiros que não estão associadas ao INBORDAL e não possuem um sistema de Identidade adequado em suas lojas, ou mesmo para o trabalho individual, não conseguem competir igualitariamente com os demais, já que seu público-alvo acaba sendo turistas que visitam o espaço (com baixo fluxo na maior parte do ano) e a população local que raramente passa pela região, seja por ser longe da maioria dos locais de fluxo da cidade ou por desinteresse e falta de conhecimento. Esse fator acaba por afetar sua renda mensal diante do público consumidor reduzido e aumentar a rivalidade mercadológica local.

Dessa forma, antes mesmo de entrarem em contato direto com a empresa, os consumidores estimam a qualidade de um produto ou serviço através de sensações e percepções que são passadas através da Identidade Visual. Portanto, quando não há esse contato inicial, pode-se perder a identidade da peça produzida, e assim comprometer a valorização das mesmas por seus consumidores. Já que, segundo Wheeler (2006):

\begin{abstract}
enquanto as marcas falam de modo virtual para a mente e para o coração, a identidade é a expressão visual e verbal de uma marca. A identidade dá apoio, expressão, comunicação, sintetiza e visualiza a marca.(...) Os melhores sistemas de identidade de marca são memoráveis, autênticos, significativos, diferenciados, sustentáveis, flexíveis e agregam valor. Seu reconhecimento é imediato, sejam quais forem as culturas e os costumes. (WHEELER, 2006, p.14).
\end{abstract}

Conforme Kotler e Keller (2006 apud Uchiyama, 2013) uma vez que a cultura está cada vez mais voltada para o visual, traduzir o significado da marca e posicionar-se por meio de design é fundamental. Desse modo, foram identificadas as necessidades da criação de um sistema de identidade visual para as bordadeiras autônomas, a fim de potencializar a comunicação dos artesãos com o seu público-alvo para que possam atender as demandas do mercado atual competitivo, e alcançar ao menos um índice de vendas similar ao índice dos bordadeiros lojistas e dos que fazem parte do Instituto INBORDAL.

\title{
4. CONCLUSÃO
}

Após a realização da análise comparativa, pode-se então identificar que quando os conceitos de design são aplicados a uma empresa, como no caso da construção da identidade visual da mesma e de seus produtos, são alcançados diversos benefícios e vantagens, tais como melhor definição e propagação das características da empresa, segurança e solidez da marca. A empresa ainda, poderá obter uma posição de destaque frente aos seus concorrentes no mercado competitivo, como é o caso dos bordadeiros vinculadas ao Instituto INBORDAL em comparação com os bordadeiros que executam o ofício de maneira independente.

E assim, valida-se a importância da marca para a construção da empresa frente ao mercado vigente e sua relação para com o consumidor, já que através da marca é possível estabelecer uma relação e criar uma ligação maior com o cliente. Desse modo, ao associar a marca, o cliente pode associá-la a características do produto, serviço e 
conceitos do empreendimento, como qualidade e esse vínculo emocional criado contribui para o fator de valorização, reconhecimento, preferência e confiabilidade no mercado.

Desse modo os bordadeiros que trabalham de forma independente podem buscar a construção de suas próprias marcas para se garantirem no mercado. Entretanto, primeiramente faz-se necessário a conscientização dos mesmos à respeito das atualizações e necessidades vigentes do comércio. Tais fatores podem ser garantidos por meio de intervenções de design com interdisciplinaridade em outras áreas de atuação, como oficinas e palestras sobre precificação e a importância de se investir em uma marca para alcançar a valorização de seus trabalhos, sem contudo modificar as propriedades culturais da tipologia artesanal desenvolvida na região, nesse caso do bordado filé do bairro do Pontal da Barra, Maceió, Alagoas.

\section{REFERÊNCIAS}

BARROS, M. C. R. 2008. 0 artesanato Alagoano: Filé. In: IV Colóquio de Moda, Novo Hamburgo, 2008. Anais: Novo Hamburgo.

INBORDAL 2017. Patrimônio Imaterial de Alagoas. Disponível em: < <http://www. inbordal.org.br/pt-br>. Acesso em 10 de junho de 2017.

PÉON, M. L. Sistemas de identidade visual. 3. ed. Rio de Janeiro: 2AB, 2003.

UCHIYAMA, A. S.; Roberto, M. M. 2013. Recepção do sistema de identidade visual em micro e pequenas empresas. In: II SEMINÁRIO DE INICIAÇÃO CIENTÍFICA DA ESPM. São Paulo.

VÁSQUEZ, R. P. 2007. Identidade de marca, gestão e comunicação. Organicom, São Paulo, v. 4, n. 7, p. 203-211, jul/dez.

WHEELER, A. 2008. Design de Identidade da Marca. 2. ed. Porto Alegre: Bookman.

Sobre os autores:

Layane Nascimento de Araújo (graduanda), UFAL <layane.n.araujo@gmail.com>

Juliana Donato de Almeida Cantalice (doutoranda), UFAL <juliana.donato@fau.ufal.br> 